OPEN ACCESS

Edited by:

Juliet Willetts,

University of Technology Sydney,

Australia

Reviewed by:

Markus Starkl,

University of Natural Resources

and Life Sciences Vienna, Austria

Alex Fischer,

University of Oxford, United Kingdom

*Correspondence:

Philippe Reymond

philippe.reymond@vuna.ch

Specialty section:

This article was submitted to Water and Wastewater Management, a section of the journal

Frontiers in Environmental Science

Received: 08 August 2019

Accepted: 12 May 2020

Published: 09 June 2020

Citation:

Reymond $P$, Chandragiri $R$ and

Ulrich L (2020) Governance

Arrangements for the Scaling Up of Small-Scale Wastewater Treatment and Reuse Systems - Lessons From India. Front. Environ. Sci. 8:72. doi: 10.3389/fenvs.2020.00072

\section{Governance Arrangements for the Scaling Up of Small-Scale Wastewater Treatment and Reuse Systems - Lessons From India}

\author{
Philippe Reymond ${ }^{1,2 *}$, Rohit Chandragiri ${ }^{3}$ and Lukas Ulrich \\ ${ }^{1}$ Eawag: Swiss Federal Institute of Aquatic Science and Technology, Dübendorf, Switzerland, ${ }^{2}$ Vuna GmbH - Spin-off \\ of Eawag, Dübendorf, Switzerland, ${ }^{3}$ Independent Consultant, Bengaluru, India
}

Environmental pollution and increasing water scarcity are key features of the urban landscape of India today. The extension of centralized sewerage networks cannot keep up with city growth, and alternative sanitation systems are needed for citywide inclusive sanitation (CWIS). The government of India mandated larger buildings to be equipped with small-scale wastewater treatment plants (SSTP). This resulted in the emergence of a large number of technology and service providers, and in the implementation of thousands of private SSTPs. However, this quick scaling up was not accompanied by the development of appropriate governance arrangements. As a result, a significant proportion of SSTPs underperform and do not meet the effluent standards. Through a systematic analysis of governance arrangements around SSTPS, this contribution analyses the scaling up process of small-scale wastewater management and reuse at building level in India, in particular in the state of Karnataka and the city of Bengaluru. This paper identifies the gaps in this multi-level, polycentric governance framework and investigates which arrangements are needed to enable the performance of SSTPs on the ground and to create the necessary synergies between the relevant governmental agencies, the private sector and civil society. The scaling up of SSTPs in India mainly followed a market governance approach within a governance environment that is traditionally very hierarchical. The authors argue that hybrid governance arrangements, blending hierarchical, market and network governance are needed to foster market regulation and stakeholder coordination, and increase the performance of the sector. They conclude that an efficient governance of SSS requires the creation of dedicated SSS units at state and city level, and the development of an online platform collating all databases, streamlining and supporting processes from establishment to monitoring, and allowing meaningful collaboration between stakeholders. Through the case study of India, this paper contributes to understand the governance arrangements necessary for the successful scaling up of decentralized sanitation systems, and how to fulfill the potential of alternative solutions for sustainable urban water management. It contributes to governance studies by substantiating the concept of hybrid governance approach and proposing concrete measures to make it work for such distributed systems.

Keywords: decentralized wastewater management, sanitation governance, polycentric governance, small-scale sanitation, sustainable urban water management, transition management, sustainability transition, water reuse 


\section{INTRODUCTION}

Small-scale sanitation (SSS, also termed "decentralized" or "distributed" sanitation), here defined as wastewater treatment systems serving from 10 to 1,000 households, have proven to be a viable alternative to conventional systems for contexts such as large residential buildings, compounds, peri-urban areas, communities and small rural settlements (Wilderer and Schreff, 2000; Newman, 2001; Parkinson and Tayler, 2003; Gikas and Tchobanoglous, 2009; Van De Meene et al., 2011; Larsen et al., 2013; Singh et al., 2015; Larsen et al., 2016). They are a key component of citywide inclusive sanitation, complementing conventional centralized sewered systems and fecal sludge management (i.e., the management of the sludge from onsite sanitation systems) (Reymond et al., 2016). While they are already widespread in rural areas in western countries, they still remain an innovative approach in most of the world. Countries like India and China are notable exceptions, first because small-scale wastewater treatment systems scaled up to thousands of units, but also because it predominantly happened in urban areas. While a key rationale for small-scale wastewater treatment in rural areas is to avoid transporting wastewater at high cost over long distances, in urban areas it is a solution to rapid urban growth and the increasing need for local water reuse.

Some of the most significant advantages of small-scale wastewater treatment systems are their flexibility, modularity, and cost-effectiveness (Massoud et al., 2009; Libralato et al., 2012), as well as increased water reuse potential (Gikas and Tchobanoglous, 2009; Larsen et al., 2016). They can be implemented in stages and dimensioned as close as possible to the actual wastewater volume, reducing the possibility of accruing idle capacity costs (Maurer, 2009). There are various reasons why conventional large-scale sanitation systems are not always the best solution for rapidly growing cities and peri-urban areas: very high capital and operational costs, the lack of stable energy supplies, spare parts and know-how for reliable operation are factors that limit their expansion (Lüthi and Panesar, 2013); the limited water availability may be another factors in some cities. From a governmental perspective, small-scale sanitation may also have the advantage to shift all or part of the investment for sanitation coverage increase to the private sector, especially to the real estate developers.

Scaling up small-scale wastewater management faces numerous challenges in many low- and middle-income countries, where it remained at pilot stage (Reymond et al., 2018). On the other extreme, where a wide scale implementation of small-scale sanitation systems happened, like in India, China and Indonesia, it often lacks appropriate governance arrangements and monitoring, which leads to a significant number of failed systems (McKinsey, 2014; Ross et al., 2014; Mitchell et al., 2015; Binz and Truffer, 2017). A "failed" system is here defined as a system that is not working according to design, and more specifically which does not fulfill the effluent standards. Successful scaling up entails more than replicating a large number of discrete projects (Eales et al., 2013). It requires innovative management and governance arrangements, financing plans and, often, bringing on board the private sector
(Willetts et al., 2007; Abeysuriya et al., 2007; Pahl-Wostl, 2009; Evans, 2013; Gebauer and Saul, 2014; Gebauer et al., 2017). Japan went this path with its Johkasou Act regulating the building-level wastewater treatment plants and related private sector service providers (MoE, 2018).

Scholars have identified numerous systemic and interrelated socio-institutional barriers impeding the implementation of sustainable urban water management (SUWM) (Mitchell, 2006; Van De Meene et al., 2011; Farrelly and Brown, 2011). Barriers include, among others, institutional fragmentation, poor political leadership, unproductive intergovernmental relations, limited long-term strategic planning, and inadequate community participation (see for e.g., Vlachos and Braga, 2001; Brown, 2005; Brown and Farrelly, 2009; Van De Meene et al., 2011; Starkl et al., 2013; Davis et al., 2019). Scaling up innovative distributed SUWM solutions requires mechanisms to strengthen multisectoral coordination, cooperation and accountability between sector departments. Governments or parastatal utilities often do not have the capacity and resources to shape and nurture a multitude of small projects (Eales et al., 2013). Smallscale systems often show a mismatch with many institutional conditions (regulations, professional codes or user expectations) (Willetts et al., 2007; Truffer et al., 2013; Binz et al., 2016). While national legislation and programs may provide important guidelines and incentives, the final functioning of the sector and the outcome in terms of actual increase in sanitation coverage with sanitation systems meeting the effluent standards crucially depends on how legislation is implemented and enforced at the local level by public as well as private stakeholders. The enabling conditions and implications for the successful operation and management of scaled up small-scale sanitation systems are addressed in few specific contexts like Indonesia (Mitchell et al., 2015) and Malaysia (Narayana, 2017). However, literature about the governance and scaling up processes of small-scale wastewater management systems in low- and middle income countries remains very scarce. Overall, governance arrangements needed to fulfill the potential of alternative sanitation solutions for urban water management need further research (Hoffmann et al., 2020).

The transition management and governance literature informs about the conditions for the successful scaling-up of distributed systems in urban water management. According to Truffer et al. (2013), the success of a scaling-up depends on the organization of innovation processes in three domains: (i) technological components and system integration, (ii) value chain formation and the development of new business models, and (iii) institutional innovations to create appropriate conditions under which these systems can reliably operate. Linked to these three domains, Binz et al. (2015) identified four key system building processes, that, taken together, enable the diffusion of radically novel socio-technical systems like SSS: knowledge creation; market formation; investment mobilization; and technology legitimation. "Technology legitimation" is defined as the "activities that embed a new technology in existing institutional structures or adapt the institutional environment to the needs of the technology." Pahl-Wostl (2009, 2019) differentiates three governance approaches which may shape 
the sector: hierarchical, market and network governance. Along with sustainability practitioners, Van De Meene et al. (2011) advocate for hybrid governance arrangements at a practical and operational level, comprising network and hierarchical approaches with market governance instruments. Moving beyond conventional approaches toward citywide inclusive sanitation needs to be both top-down and bottom-up (Reymond et al., 2016). The classical distinction between hierarchies, networks and markets as ideal-typical governance modes has proven to be very useful for analyzing complex and hybrid governance settings (Pahl-Wostl, 2019). The conceptual basis provided by Truffer, Binz, Pahl-Wostl and Van de Meene will be used to understand the findings about the SSS sector in India and frame the authors' recommendations about improved governance arrangements.

Klinger et al. (2020) estimated that more than 20,000 smallscale wastewater treatment plants (SSTPs), mostly privately funded, were implemented in India following a policy drive for decentralized sanitation systems, aiming to address fast urban growth, an increasing water scarcity, and the need for more water reuse (MoEF, 2006). In Bengaluru, SSS has an installed capacity to treat an estimated $10-20 \%$ of the city's sewage (Kuttuva et al., 2018; Srinavas, 2018). This quick and unprecedented scaling up process of SSS in large buildings has not been thoroughly studied, and lessons learnt are scarce. Studies are hindered by the lack of a centralized database and the nature of the SSTPs (privately owned and privately managed, and often hard to access). The governance framework did not develop at the same pace as the implementation of the SSTPs, and the governmental bodies are still not fully equipped to monitor the scaling up process and the performance of the systems. Studies have found that many of these SSTPs are experiencing performance problems (Suneethi et al., 2015; Chatterjee et al., 2016; Starkl et al., 2018; Klinger et al., 2020).

Through a systematic analysis of governance arrangements around small-scale wastewater treatment and reuse systems, this paper identifies the gaps and loopholes in the current governance framework for SSTPs at building (or cluster of buildings) level in India and in the state of Karnataka in particular. It proposes measures to optimize the efficiency of policies and create synergies between the different relevant governmental agencies. In this paper, "governance" refers to the rules, roles and relations that make sanitation systems work. It includes the formulation, establishment and implementation of sanitation policies, legislation and institutions, and clarification of the roles and responsibilities of government, civil society and the private sector in relation to sanitation systems and services (UNDP-SIWI, 2016a,b). Institutions are used here according to the convention in institutional analyses in the social sciences to denote rules governing the behavior of actors (Pahl-Wostl, 2009): "Institutions do not refer to organizations or physical structures. Formal and informal institutions refer to nature of processes of development, codification, communication and enforcement." The governance framework in India involves multiple stakeholders at national, state and city level. It is a multilevel, polycentric governance system, a concept which Pahl-Wostl (2009) defines as a "complex, modular system where differently sized governance units with different purpose, organization, spatial location interact to form together a largely self-organized governance regime."

In this contribution, the authors (i) analyze the scaling up process and governance framework of small-scale wastewater management at building (or cluster of buildings) level in India; (ii) analyze the particular case of the state of Karnataka and its capital city Bengaluru, which are spearheading the implementation of SSS systems in India; (iii) identify the gaps in the governance framework; and (iv) propose governance arrangements which foster the performance of SSTPs and the creation of the necessary synergies between the relevant governmental agencies, the private sector and civil society. Despite the complexity of Indian institutions, the case of Karnataka and Bengaluru is quite typical of the issues faced by governments when scaling up innovative systems such as small-scale wastewater treatment plants. It can thus inform similar processes in many countries worldwide, especially in terms of administrative processes and governance arrangements which allow economies of scale and proper monitoring. It also provides an insight on how to deal with multi-level, polycentric governance systems in sustainable urban water management and substantiates the concept of hybrid governance approach for distributed systems.

\section{METHODOLOGY}

The results presented in this paper are part of a broader study on small-scale sanitation in India consisting of three components: (i) a technical analysis; (ii) a financial analysis; (iii) a governance analysis. The technical analysis consisted of a questionnairebased assessment of 279 SSTPs in the field, as well as three rounds of 24-h effluent sampling in 35 of them (Klinger et al., 2020). In this paper, reference will be made to Klinger et al. (2020) when building on methodologies and results from the technical analysis component. The structured questionnaire was performed with SSTP managers, operators, and users when available. It provides insights on the performance of SSTPs, operation and maintenance, reuse practices, general perception of users and the skills and training level of the managers and operators, and informs about the effects of the governance framework on the ground.

The methodology used specifically for the governance analysis component consists of a mix of qualitative methods:

- A review of the policies, laws and regulations around smallscale wastewater treatment in India, with a special focus on the state of Karnataka.

- Identification of key public and private stakeholders at national level, in the state of Karnataka, and in the city of Bengaluru.

- Desk-based stakeholder and procedure mapping and analysis of the stakeholders' roles and responsibilities along the project cycle of SSTPs.

- Semi-structured qualitative expert interviews with key informants of the sector, aiming to get a general 
understanding of the situation. These interviews were conducted by the project team in different local languages, and were not recorded as many stakeholders, especially government stakeholders, are afraid that truthful answers could be used against them. For that reason focus was given on trust-building and informality. Key information was then extracted and compiled.

- Consultations and informal discussions with sector experts and concerned citizens.

Thirty-five key informants were interviewed from different groups, as synthesized in Table $\mathbf{1}$. Table $\mathbf{1}$ does not include the stakeholders interviewed during the assessment of the 279 SSTPs. Knoke (1996) and Fischer et al. (2017) propose a systematic strategy for identifying stakeholders in a policy sector, relying on three criteria: (i) "decisional criteria": those stakeholders that participate in important decision-making venues of the sector; (ii) "positional criteria": those stakeholders that are in an institutional position to influence the policy sector; (iii) "reputational criteria": those stakeholders that are identified by other stakeholders as being influential in the policy sector. During interviews, respondents were asked to mention important stakeholders not identified at first (snowball principle). This strategy of relying on "crowd knowledge" ensured that the study captured the most important stakeholders. The higher number of interviews with governmental stakeholders at state level and with private sector stakeholders reflect the fact that sanitation is primarily a state-level matter and that SSS is mainly driven by the private sector.

The governance issues are thus analyzed both from the top (the national and state policy level) and from the bottom (the impact at sanitation system level). The analysis looks at the overall governance framework for small-scale sanitation, and at the governance arrangements along the project cycle of SSTPs. This approach allowed to obtain an understanding of the strengths and weaknesses of the current governance framework and to identify key factors impairing the efficiency of SSS at scale. The results were then reflected through the conceptual framework provided by Pahl-Wostl (2009), Van De Meene et al. (2011), Truffer et al. (2013), and Binz et al. (2015), presented in the introduction.

The governance framework for small-scale wastewater treatment slightly differs in every Indian state. This paper focusses particularly on the state of Karnataka, as it is the most advanced state respective to SSS (advanced policies and highest numbers of units) and is therefore appropriate to understand the challenges of the scaling up process. Such challenges are not

TABLE 1 | Number of interviewees per stakeholder group.

Stakeholder group

Governmental agencies at national level

Governmental agencies at state level

Governmental agencies at city level

Private sector

NGO
Number of interviewees (yet) apparent in other states that do not implement small-scale wastewater treatment policies to the same extent. Although this approach gives a good overview of what the challenges can be and what is needed for an efficient governance framework around SSS, it remains a partial view, and cannot fully represent what is happening all around India. In order to achieve the latter goal, an analysis of the governance framework in each state in view of our findings would be needed.

\section{REVIEW OF THE POLICIES, LAWS AND REGULATIONS}

Small-scale sanitation is increasingly contributing to sanitation coverage in urban India, and is imposing itself as a key component of citywide inclusive sanitation in the country's cities, next to conventional centralized systems and fecal sludge management (FSM) (Ulrich, 2018). SSS systems have the potential to complement large-scale plants in the non-sewered zones of cities, while significantly reducing the time needed for planning and implementation. Besides, shortage of funds has not been able to allow for the blanket coverage of entire cities with a centralized sewer network (Singh et al., 2018). However, whereas the governance framework for centralized systems is already established and the one for FSM under quick development, the governance framework of small-scale sanitation is still weak, despite its growing role in increasing sanitation coverage, water reuse and protecting the environment. Besides, as with many environmental policies in India (Brunner et al., 2010; Sakthivel et al., 2015), there is an important gap between the policies and the actual implementation on the ground.

Urban wastewater management in India is mainly driven by the Ministry of Housing and Urban Affairs (MoHUA), the Ministry of Environment, Forest and Climate Change (MoEFCC) and their line agencies, as illustrated in Figure 1. In the Constitution of India, the responsibility of sanitation is delegated to the states, under purview of MoHUA (formerly Ministry of Urban Development - MoUD) at national level. Constitutionally, MoHUA's role is confined to advocate policies, design guidelines and standards, clearly demarcating sanitation as a state subject (Bhullar, 2013). MoHUA is the principal policy-making agency in the field of urban sanitation and also largest funder of the sector (Wankhade, 2015). State governments are vested with powers to legislate on sanitation either directly or indirectly. With the enforcement of the 74th constitutional amendment in 1992, Urban Local Bodies (ULBs), which are in charge of approving new buildings, are given the responsibility of devising and implementing sanitation strategies. In a few metropolitan cities, utilities are responsible to deliver water supply and sewerage services (Water Supply and Sewerage Boards - WSSB). Such bodies are partly or wholly owned or controlled by state government (Bhullar, 2013). Where a WSSB exists, it takes over the responsibility of sanitation from the ULB. In that case, the ULB's role is limited to devising building regulations, which can encourage small-scale sanitation.

In practice, ULBs and WSSBs (in metropolitan cities) do not have sufficient institutional and financial capacities to 


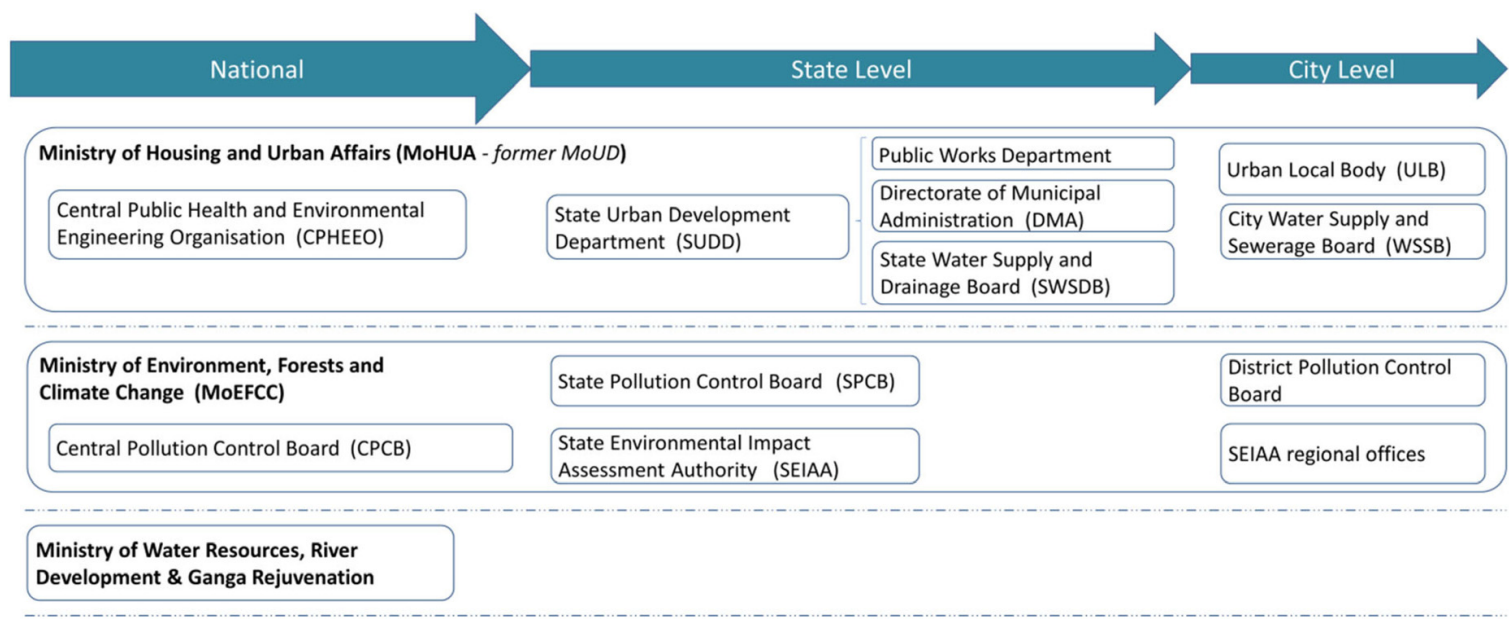

FIGURE 1 | Government agencies responsible for urban wastewater management in India (in January 2019).

build, operate and maintain sewage infrastructure with city-wide coverage (Ahluwalia, 2011; Planning Commission, 2011). To tackle the gaps in provision of sewage collection and treatment services in the absence of a WSSB, State Water Supply and Drainage Boards (SWSDBs) were formed at state level to support ULBs in planning, designing and implementing sewerage and wastewater treatment infrastructure. SWSDBs draw funds from national and state governments. They can build treatment plants and then hand them over to ULBs for operation and maintenance. Similarly, parastatal agencies also rely on state government or donor agencies for financial resources to construct large-scale wastewater management infrastructure.

Ministry of Environment, Forest and Climate Change and line agencies are in charge of minimizing environmental pollution, as well as planning, promoting and coordinating environmental policies and programs in the country. They are responsible for setting environmental standards (especially the discharge standards for treated wastewater). The Central Pollution Control Board (СРCB) was constituted under the Water Act in 1974 as a line agency of MoEFCC with the responsibility to prevent, control and abate environmental pollution and to set the wastewater discharge standards for the entire country. All the sewage treatment plants in India should adhere to the standards issued by CPCB. At state level, State Pollution Control Boards (SPCBs) are responsible for the implementation of legislations related to environmental pollution. SPCBs are provided freedom to toughen the regulations enforced by CPCB. SPCBs are responsible to monitor the performance of all wastewater discharging entities (buildings, industries, large and small-scale sanitation systems).

Recognizing that Indian cities grew faster than the pace at which centralized wastewater management systems could be extended, the Ministry of Environment and Forests (today MoEFCC) prescribed SSS systems for large residential, institutional and commercial buildings in 2004 through an amendment to the Environmental Impact Assessment (EIA) notification (MoEF, 2004). MoEF further amended the EIA notification in 2006, prescribing SSS for buildings with a total built up area above $20,000 \mathrm{~m}^{2}$ throughout the country (MoEF, 2006). The key rationale behind EIA notification 2006 is that large buildings tend to have a greater environmental impact and mandating SSS was a mitigating measure. This national policy was followed by uptake and adaptation to various extents at state and at city levels, which generated a boom in private sector small-scale wastewater treatment service providers (Klinger et al., 2020). SSS was fostered in various policy guiding documents, 'model building bylaws' and small-scale wastewater management guidelines, which are suggestive measures leaving enforcement and application to the willingness of Urban Local Bodies.

Several SPCBs decided the application of a stricter threshold for the construction of SSS, like in the case of Karnataka. Thousands of units have been implemented since then throughout India (Klinger et al., 2020). In view of increasing water scarcity and the high price of conventional centralized systems, scaling up of SSS will only accelerate in the years to come.

\section{FACTORS IMPAIRING THE EFFICIENCY OF SSS AT SCALE}

The assessment of 279 SSTPs showed that a large number of SSTPs do not perform according to their technical design and to the effluent standards (Klinger et al., 2020). Effluent quality was tested for 35 of these plants, which showed that more than two thirds from all categories of treatment technologies exceeded BOD standards at least in one sample, and microbial quality of effluent consistently did not meet CPCB standards in almost all systems analyzed (Klinger et al., 2020). This provides evidence that the current governance framework for small-scale wastewater treatment systems does not provide the necessary incentives to guarantee system performance on a wide scale. The governance analysis shows that weaknesses exist at all governance levels, from the governance arrangements at national level to the 
details of the implementation and operation processes of smallscale wastewater treatment systems. Based on the analysis, the authors conclude that, from a governance perspective, the overall performance and success of small-scale wastewater treatment in India is impaired by a number of interlinked factors:

(i) Lack of recognition of SSS by the government agencies responsible for urban sanitation planning;

(ii) Lack of coordination between relevant governmental agencies;

(iii) Lack of dedicated budget and human resources for consent delivery and monitoring;

(iv) Loopholes in the establishment, handover and monitoring procedures;

(v) Inadequate operation \& maintenance (O\&M);

(vi) No specific effluent and reuse standards for SSTPs;

(vii) Insufficient integration of SSS in water reuse planning;

(viii) Lack of key centralized governance structures, such as training and information platforms.

The results for each of these aspects are developed in the following paragraphs.

\section{Lack of Recognition of SSS}

The study highlights that although more than 20,000 small-scale wastewater treatment systems were constructed in India with an ongoing increase, the authorities in charge of sanitation planning (MoHUA and line agencies) are unaware of the number and location of these systems (Klinger et al., 2020). SPCBs and SEIAA are the only agencies which possess some databases, but the latter are not harmonized nor digitized. As a consequence, SSS is still not on the sanitation map next to conventional centralized wastewater management and FSM. The analysis shows that it is because the drive for small-scale wastewater systems did not come from the governmental agencies in charge of the wastewater sector (i.e., MoHUA and line agencies at state and city levels), but from MoEFCC and line agencies, based on an environment protection and sometimes water saving rationale. Based on the review of policies, laws and regulations, Figure 2 highlights how the roles and responsibilities dramatically differ between largescale and small-scale wastewater management in terms of policy, funding and implementation. For the former, MoHUA and line agencies are entirely in charge, whereas MoHUA is almost absent from the current small-scale wastewater management sector. The latter is under the responsibility of MoEFCC and line agencies and the private sector. In particular, funding and implementation of SSS are entirely delegated to the private sector.

The governmental agencies that are in charge of urban sanitation planning do not have the overview of the growing number of SSS systems and their functional status. As highlighted by Reymond et al. (2018), government agencies are often risk averse and reluctant to get out of business-as-usual and to take up responsibilities on new systems that seem to demand important budget and human resources. Despite the growing contribution of SSS to sanitation coverage, the WSSBs and ULBs, which are the governmental bodies in charge of sanitation planning at local level, do not show ownership for small-scale systems, nor do they integrate them in their sanitation masterplans. The main responsibility as well as most of the existing information regarding SSS are in the hands of the State Pollution Control Boards, although they are only in charge of monitoring and not sanitation planning per se. There are attempts to involve the ULBs in monitoring of SSS, but this was not enforced at the time of the study.

\section{Lack of Coordination Between Relevant Governmental Agencies}

The lack of coordination manifests itself in different domains: databases; policies; planning. Currently, Indian states and cities do not have a comprehensive electronic database of smallscale wastewater treatment systems (unified across states and, more importantly, among their own governmental agencies) (Klinger et al., 2020). A lot of information is still being stored on paper (e.g., sampling results). State pollution control boards, the regulatory agencies in charge of approving and monitoring SSS at state level, do not have a curated, upto-date database in electronic form. This impairs proper georeferencing and monitoring of SSTPs, which would be the basis for further urban planning, including the development of efficient water reuse strategies and assessment of the sanitation coverage.

Policies are not coordinated, as highlighted by the lack of recognition of SSS by MoHUA and line agencies and their investment strategies. Finally, urban planning is not coordinated, which sometimes results in double investment, e.g., in cases where an SSTP is mandated in a building that will be shortly connected to the main sewer network.

\section{Lack of Dedicated Budget and Human Resources}

The policies devised by the Indian government were successful in enforcing the implementation of SSS in certain building categories. Interview results and visits to relevant government agencies tend to confirm that they were not followed by the budget and human resources allocation necessary to monitor the implementation and operation of thousands of units, nor were the institutions governing these prepared to the management of a large number of distributed systems. Similar to the situation in other emerging economies (Binz and Truffer, 2017), SSS systems thus got successfully installed, yet without the creation of an actor network, financial infrastructure and institutional arrangements that would be able to effectively monitor the spatially dispersed plants and enforce regulation.

The authors assume that it is a main cause for the following shortcomings, highlighted during the interviews of experts and own observations:

- General lack of human resources dedicated to SSS, especially in the SPCBs for monitoring; 


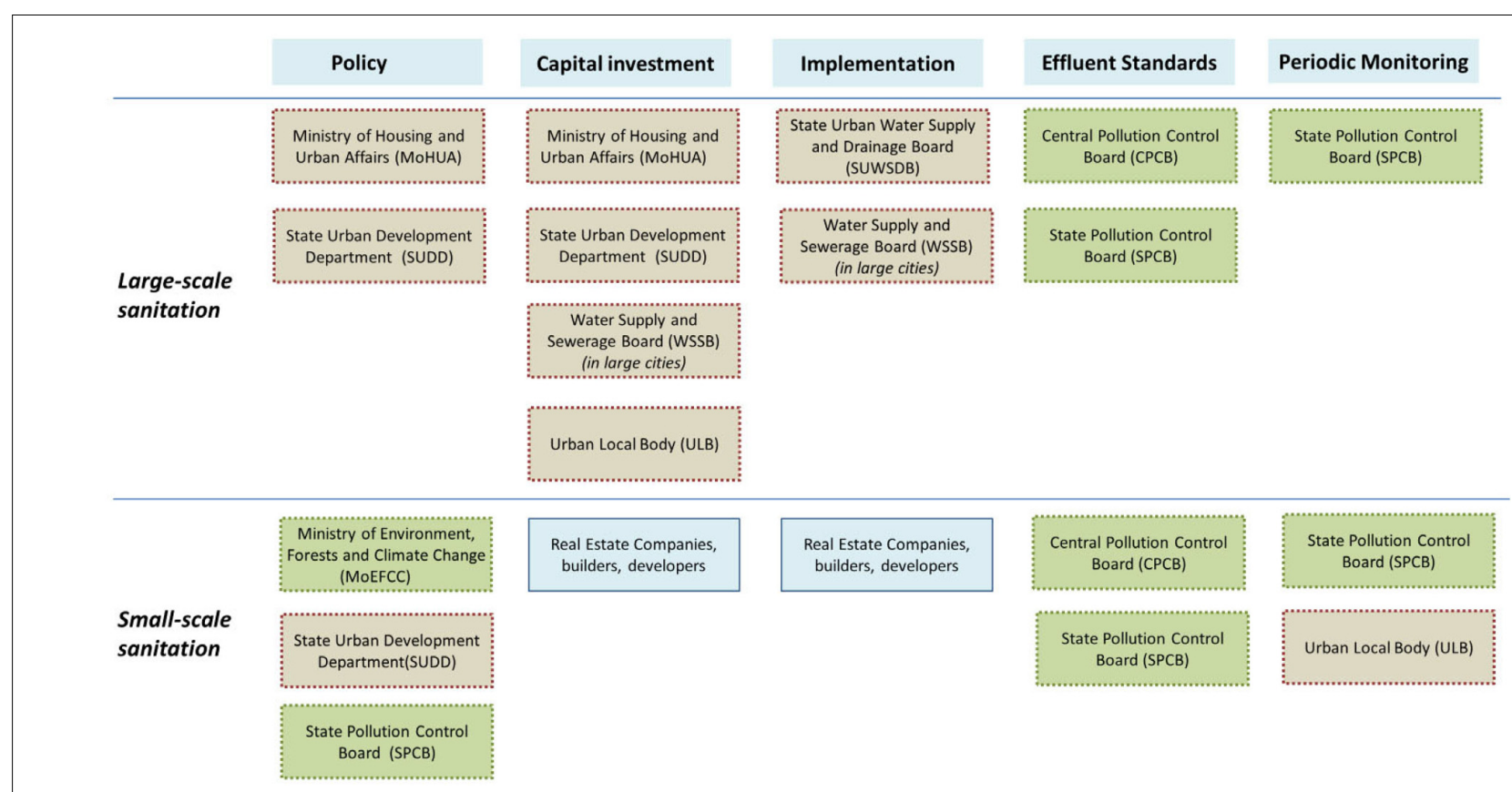

FIGURE 2 | Comparison of responsibilities in the large-scale and small-scale sanitation sectors; the governmental agencies highlighted in brown fall under MoHUA and the ones in green under MoEFCC.

- Lack of technical support for planning, operation and maintenance of such systems from the responsible government agencies to the private sector;

- Lack of capacity building and training, both for government workers and private service providers;

- Inadequate monitoring mechanisms due to lack of funds, lack of staff and lack of coordination between governmental agencies;

- Weak enforcement of laws and regulations and insufficient penalization.

\section{Loopholes in the Establishment, Handover and Monitoring Procedures}

The procedures to establish and monitor private small-scale wastewater treatment systems were systematically analyzed for the case of the state of Karnataka, through desk-based research and discussion with experts. The process can be broken down into (a) the preliminary approval, obtained through the building approval; (b) design; (c) implementation; (d) postimplementation check, start of operation and handover; (e) monitoring. Real estate developers appoint SSS designers. There are two types of consents required to establish and operate SSS systems, which are granted by the State Pollution Control Board (SPCB) for projects with an area below 20,000 $\mathrm{m}^{2}$ in Karnataka: (a) the Consent to Establish (CTE), to be obtained at the end of the design phase, and (b) the Consent to Operate (CTO), to be obtained at the end of the implementation phase, before the commissioning of the plant, and to be renewed at a defined frequency. Inspectors from the Water Supply and Sewerage Board (WSSB) in large cities or from the ULB in small and medium towns carry out inspections once the whole building is complete, which mainly focus on setbacks, height of the building and presence of the SSS system. There are no defined guidelines for the validation of SSS systems for any available technology.

In the residential context, real estate companies (builders) are responsible for the operation and maintenance of the systems until a formal resident welfare association (RWA) is formed. Then, the newly constituted RWA has to take up the responsibility for the systems. There is no defined period since real estate companies are obliged to maintain all the common areas within the building premises till the creation of the RWA.

The study highlights the main weaknesses along the establishment, handover and monitoring procedures. Figure 3 illustrates these weaknesses by representing the different interactions between the government agencies and the private sector in the state of Karnataka. The private sector is responsible for planning, design, implementation and operation and maintenance, whereas the main roles of the government agencies are consent issuance and monitoring. The numbers in the list below refer to the number tags in Figure 3, placed at the relevant location on the stakeholder and processes map:

1. Technology selection which is not based on long-term sustainability and life-cycle cost of the future treatment plant: the stakeholders in charge of technology selection are usually not the ones who will operate the plant on the long-term (real estate developers vs. building management body) (Klinger et al., 2020). Capital costs are the main selection criteria, and not O\&M cost. Life cycle costs and management implications are not taken into consideration. Besides, there is insufficient knowledge of the different options and the implications of choices; 


\section{GOVERNMENTAL AGENCIES}

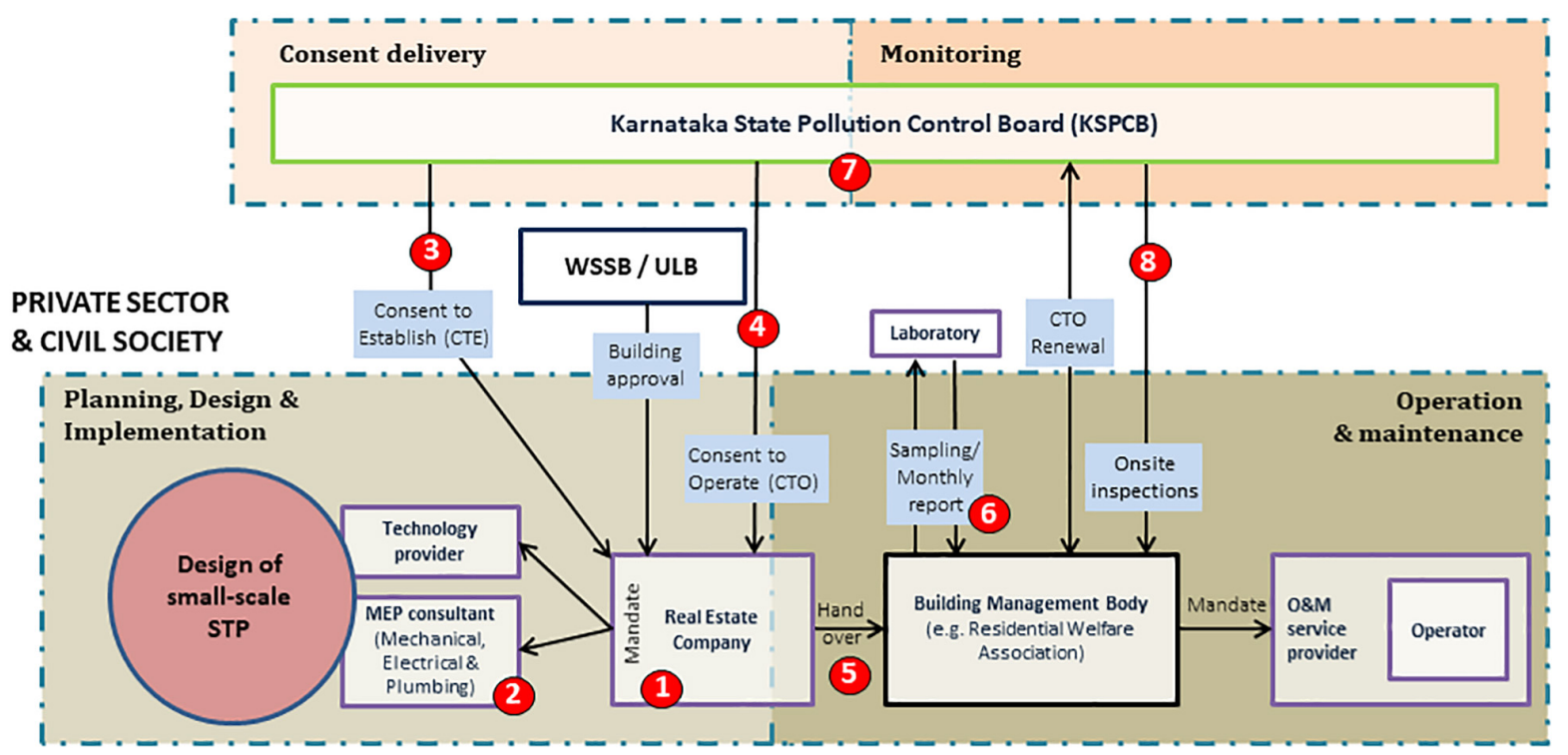

FIGURE 3 | Stakeholders, procedures and governance arrangements through the life-cycle of a small-scale wastewater treatment system in the state of Karnataka. The red numbers refer to the main weaknesses explained in the text.

relevant governmental bodies do not provide guidance nor control.

2. Unqualified consultants: lack of experience and expertise for design and implementation on the side of consultants, such as Mechanical, Electrical and Plumbing (MEP) consultants.

3. Consent to Establish: lack of rigor in design evaluation, mainly linked to a lack of capacities and guiding documents.

4. Consent to Operate: lack of capacities at PCB to carry out an effective inspection of the infrastructure.

5. Handover: absence of formal transfer process between (most often) the real estate company and the building management body (e.g., a RWA). The newly constituted building management bodies were not involved in technology decisions, are not well prepared to assume their new operational responsibilities, and the relevant training and documentation is often lacking.

6. Sampling and reporting: the building management body takes samples and sends them to a certified laboratory. The laboratory sends the results back to the building management entity, who then transfers them to the PCB. This results in a high risk of data manipulation during one of the different steps of the process.

7. Inexistence of unified, georeferenced online database of SSTPS: this results in a difficulty for the PCB and other agencies involved to track the SSTPs.

8. Lack of financial and human resources for the PCB to do sufficient onsite inspections.

Although this process bears the features of a hierarchical governance approach, the lack of guidance, competency, resources and enforcement leaves a lot of freedom to the private sector. The authors argue that in such a weak hierarchical governance framework, market governance dominates de facto. The market grew with very little restriction from the government, and the lack of capacities and enforcement of the latter enables the different private stakeholders to easily work around the regulations.

\section{Inadequate Operation \& Maintenance}

The operation and maintenance (O\&M) of SSTPs is under the responsibility of the real estate developer or the building management body, and the assessment of 279 SSTPs found that many systems were not properly operated (Klinger et al., 2020). The private sector plays a key role in the operation and maintenance. Different management arrangements exist: (a) real estate companies keep the responsibility of O\&M against a fee, (b) the entire operation and maintenance is outsourced to a private player based on annual contracts, (c) skilled operational personnel is hired to run the systems, or (d) RWA manages on their own with the available local staff (mostly unskilled). Whatever arrangement is in place, there is a lack of capacity of building owners to hold contracted service providers accountable (Klinger et al., 2020).

The field survey questionnaire to SSTP operators about their education and training level showed that they often do not have the required skills nor the understanding of the treatment processes at stake (Klinger et al., 2020). This is also confirmed by the findings from Suneethi et al. (2015), Chatterjee et al. (2016) and Davis et al. (2019). The latter highlight that the lack of technical support, lack of clear O\&M plans and insufficient O\&M funds are major failure factors for SSS in India. There are no licensing/certification mechanisms and no training available. 
The operators are often left alone, and the SSTPs are often not operated toward performance, but cost reduction: the O\&M service provider or building management body may run the treatment plant in order to reduce the energy costs, in a way that can be detrimental to the treatment performance (Chatterjee et al., 2016; Klinger et al., 2020). There is insufficient incentive to properly operate plants. In some cases, water reuse may play as an incentive, especially where treated wastewater is used for toilet flushing (Klinger et al., 2020).

The review of regulations show that they do not state how the systems should be operated. Guidelines for operation and maintenance for wastewater treatment systems are developed by line agencies of MoHUA, but it was not done for SSS due to the lack of institutional ownership. The lack of proper monitoring from the relevant government agencies leaves a poor O\&M by the responsible private or civil society stakeholders largely without consequence.

This study did not allow showing clearly if one management arrangement leads to better treatment performance outcomes than the others. Further research comparing management and contractual arrangements is needed. The authors assume that awarding performance-based contracts to private companies specialized in O\&M of SSTPs is the most promising schemes. Increasing service provider accountability through design-buildoperate contracts should also be considered.

\section{No Specific Effluent and Reuse Standards for SSTPs}

The Indian effluent discharge standards apply for all wastewater treatment plants; there is no specific discharge standards for small-scale systems. The standards prescribed by the Central Pollution Control Board (CPCB) are mandatorily applicable throughout the country. However, state pollution control boards (SPCBs) have the freedom to toughen these regulations and standards. SSS have to adhere with the standards set by the SPCBs. The state of Karnataka adhered to the latest modifications in 2018 after having been more stringent than the national standards: treatment plants in metro cities and all the major state capitals should now adhere to BOD $<20 \mathrm{mg} / \mathrm{L}$.

Starkl et al. (2018) and Klinger et al. (2020) showed that the standards are too stringent for most SSTPs to comply. As effluent sampling is left to the entity responsible for O\&M, and there is little direct monitoring by the government, SSTP owners have little incentive to comply. Standards that are realistically difficult to meet combined with a weak monitoring framework, leads SSTP owners to focus on circumventing the monitoring system in place rather than investing in improving the performance of their plant. The authors would advocate for more network governance allowing a transparent discussion between SSTP owners and the governmental agencies in charge of setting the standards. The review of newspaper articles showed that the civil society and private sector are currently not involved in the development of standards, but can influence them retroactively at state level through collective action.

The interviews of experts showed that the introduction of differentiated standards for different reuse purposes is debated.
On the one hand, such measure can provide incentives to SSTP owners, but on the other side, it is very difficult to monitor and enforce, and may lead to new loopholes. Besides, tightening standards may overtask the government agencies in charge (Starkl et al., 2018).

\section{Insufficient Integration of SSS in Water Reuse Planning}

Water reuse policies can trigger SSS (Larsen et al., 2013). MoHUA's National Urban Sanitation Policy (NUSP) of 2008 (MoUD, 2008) encourages reuse of reclaimed water, especially for construction, irrigation and gardening, and recommends a minimum of $20 \%$ reuse of wastewater in every city. The National Water Policy from 2012 promotes and incentivizes the reuse of wastewater (MoWR, 2012). Bylaws for the construction industry and power plants state that only treated wastewater should be used (Never, 2016). SSS, through its distributed nature, fosters the onsite or neighborhood-level reuse of treated wastewater. It thus plays a crucial role in fulfilling water reuse strategies, but its potential role and advantages compared to conventional sewered systems are not fully taken into account by the responsible government agencies.

Some states and cities proactively developed policies to bring these concepts closer to the ground. Already in 2003, in a situation of drinking water shortage, Karnataka issued a government order for Bengaluru, making it mandatory to use tertiary treated water for non-potable purposes, with penal provisions in case of non-compliance. The order clearly states that the Bengaluru Water Supply and Sewerage Board (BWSSB) shall not provide potable water supply for activities including gardening, vehicle cleaning and construction (GoK, 2003). In 2015, The Karnataka State Pollution Control Board issued an order which stipulates that secondary treated sewage mandatorily be sold for use for non-potable purposes, such as industrial use, railway and bus cleaning, flushing of toilets, horticulture and irrigation (KSPCB, 2015). According to that order, no potable water shall be allowed for such activities. The enforcement is, however, difficult and not strictly done. Nonetheless, the present study shows that the reuse of treated wastewater from SSS is widely practiced in Bengaluru and the other surveyed cities. While it is hard to quantify the actual amount of water reused, the field survey showed that more than $75 \%$ of the studied 279 systems reused at least parts of the treated water for irrigation, toilet flushing and sometimes air conditioning (Klinger et al., 2020).

\section{Lack of Key Centralized Governance Structures}

The study shows that the potential for economies of scale at government and private sector levels is hardly exploited. Numerous private sector stakeholders are competing for technology provision and O\&M service provision (Klinger et al., 2020). Despite the high number of units, the management schemes are very diverse and scattered, with hardly any monitoring. Operators are left alone, without a network to rely on. The observed market governance approach lacks 
centralized coordination around urban development plans, linked with monitoring and enforcement to ensure performance meets standards. Besides, training programs for operators and municipal sanitation officers are lacking. This results in the observed shortcomings not being addressed, the best practice not incentivized, and the absence of an information sharing platform.

A higher degree of centralization would benefit the performance of the sector, especially for O\&M and training, and robust standardized monitoring structures would allow sector learning and optimization.

\section{MEASURES RECOMMENDED TO IMPROVE THE GOVERNANCE OF SSS}

The governance analysis presented in this paper shows that the scaling up of small-scale wastewater treatment and reuse systems in India mainly follows a market governance approach and is very little impregnated by network governance. Even though the hierarchical governance approach is dominant in India, the lack of coordination of the different government agencies resulted in market governance playing a crucial role. More centralized coordination, especially around monitoring, enforcement and training, and to some extent more network governance with intermediary structures linking effectively the different government agencies, the private sector and the civil society (mainly represented by building owners associations), are needed for a more robust governance framework. This tends to confirm the claim by Van De Meene et al. (2011), Pahl-Wostl (2009), and other scholars that hybrid governance frameworks are likely to deliver more sustainable outcomes. This study also reinforces the findings from Van De Meene et al. (2011) highlighting the practitioners' perception that the hybrid governance approach would facilitate sustainable urban water management.

This analysis shows that among the three domains pointed out by Truffer et al. (2013) for a successful scaling up, the "technological components and system integration" materialized through the private sector, as well as the "value chain formation and the development of new business models"; these include the "market formation" and "investment mobilization" mentioned by Binz et al. (2015). The market formation is well advanced, except for the services around O\&M which still show development potential. "Knowledge creation", another key system building processes identified by Binz et al. (2015), is led by the private sector, but was not yet transferred to the relevant governmental agencies and translated into guidelines because of the lack of knowledge sharing and the lack of a structured monitoring that would allow lessons learnt and the diffusion of best practice. The "institutional innovations to create appropriate conditions under which these systems can reliably operate", third domain pointed by Truffer et al., are still not adequately developed. While SSS is explicitly mentioned in regulations, and increasingly in water reuse policies, the structures that can guarantee its performance are still not mature, because the legitimacy of SSS is not yet anchored in MoHUA and line agencies. This is in line with Binz et al. (2016), who argue that the successful scaling up of innovations crucially depends on technology legitimation by the main stakeholders, from the user to the relevant government agencies.

The authors identify the main weaknesses in the governance framework and recommend measures to address them. Table 2 synthesizes the authors' recommendations. Most proposed measures are geared toward more effectiveness and efficiency of the hierarchical governance, as it remains the main driver of policy change in India. The need for new hierarchical governance structures to strengthen the centralized monitoring of SSTPs and the overall coordination of the sector is reflected in the two following key proposals, as illustrated in red in Figure 4 (adapted from Figure 3):

1. Creation of an online platform for small-scale wastewater treatment plants, functioning as a unified database to which all relevant governmental agencies have access and where all the documents and information related to each unit are collated via a unique ID for each plant.

2. Creation of dedicated governmental SSS units at state level, with sub-units in every city, embedded in the Water Supply and Sewerage Board (WSSB) where existing or in the Urban Local Body (ULB) otherwise. This is justified by the need for a higher coherence of urban water and wastewater management planning at city level. It is recommended that these agencies take over the oversight responsibility of SSS. PCBs would remain the main agency in charge of long-term monitoring, as per their constitutional mandate.

An online platform is seen as a powerful tool for urban water management and infrastructure planning, partially automated performance monitoring, as well as sector learning and benchmarking. It would contribute to clearly locate SSS next to conventional wastewater management and FSM in citywide inclusive sanitation. Such a platform would be well aligned with the current digitalization trend in India. Digitalization is increasingly implemented and fostered by the Government of India, for example in these initiatives: Digital India Mission, Swachh Barat Toilets with GIS tracking, consent management platform in the state of Tamil Nadu, National rural drinking water monitoring (Wescoat et al., 2016), etc.

The authors recommend that these two structures be endorsed at national level, but developed and validated at city and state level. Testing and validating the new structures in a progressive state would allow to make them more robust, create a role model and facilitate their replication in the other states. The state of Karnataka could take the role of pioneer state, as it is currently spearheading the scaling up of SSS in India and is experiencing serious water scarcity.

The two proposed structures would strengthen the technology legitimation, knowledge creation and monitoring \& evaluation of SSS and thus create "appropriate conditions under which these systems can reliably operate." They have the potential to improve the current governance framework, through:

1. Facilitating the merging and completing of existing databases, standardizing data collection and removing certain loopholes. 
TABLE 2 | Weaknesses in the governance framework and measures recommended by the authors.

\begin{tabular}{|c|c|}
\hline $\begin{array}{l}\text { Weaknesses in the governance } \\
\text { framework }\end{array}$ & Possible measures \\
\hline $\begin{array}{l}\text { Recognition of SSS by the } \\
\text { governmental agencies responsible for } \\
\text { urban sanitation planning }\end{array}$ & $\begin{array}{l}\text { - Specify role and scope of SSS in national policies, state sanitation strategies and city sanitation plans } \\
\text { - MoHUA: develop technical specifications and guidelines, so that funds can be channeled for SSS from national level } \\
\text { down to ULBs and WSSBs } \\
\text { - Create a unified database of SSTPS, with georeferenced data } \\
\text { - Draw statistics on the contribution of SSS to urban sanitation coverage, and introduction of a SSS category in } \\
\text { the census }\end{array}$ \\
\hline $\begin{array}{l}\text { Coordination between governmental } \\
\text { agencies }\end{array}$ & - Online platform with unified database \\
\hline $\begin{array}{l}\text { Lack of dedicated budget and human } \\
\text { resources }\end{array}$ & $\begin{array}{l}\text { - Create dedicated SSS units at state and city level to monitor SSS implementation and operation and to provide } \\
\text { technical assistance if needed. } \\
\text { - Provide training to staff of SSS units and SSTP operators through capacitated training centers }\end{array}$ \\
\hline $\begin{array}{l}\text { Loopholes in the establishment, } \\
\text { handover and monitoring procedures }\end{array}$ & $\begin{array}{l}\text { - Online platform centralizing all information for each SSTP } \\
\text { - Management of building approval, CTE and CTO by the same governmental agency } \\
\text { - Create dedicated SSS units at state and city level } \\
\text { - Standardized handover between real estate developers and building management body } \\
\text { - Create mechanisms increasing the accountability of real estate developers in technology selection and design } \\
\text { - Automated verification procedures and prioritization of field visits } \\
\text { - Streamline sample management, with results directly uploaded on the online platform by certified laboratories }\end{array}$ \\
\hline Operation \& maintenance & $\begin{array}{l}\text { - Delegate management to specialized private service providers managing the O\&M of several SSTPS, along with } \\
\text { performance-based contracts } \\
\text { - Certification/licensing of O\&M service providers } \\
\text { - Develop financial incentives for building management bodies (e.g., property tax rebate) } \\
\text { - Create an operator network allowing experience exchange and cross-fertilization }\end{array}$ \\
\hline Effluent standards & - Develop effluent standards that are specific to SSS and reuse purposes \\
\hline $\begin{array}{l}\text { Insufficient integration in water reuse } \\
\text { planning }\end{array}$ & $\begin{array}{l}\text { - Specify role and scope of SSS in water reuse policies } \\
\text { - Geo-reference the SSTPS } \\
\text { - Draw statistics on the contribution of SSS to water reuse } \\
\text { - Develop an app to link supply and demand of treated wastewater } \\
\text { - Higher level of centralization (cluster of buildings, street) if water reuse is not possible at building-level }\end{array}$ \\
\hline Key centralized institutional structures & $\begin{array}{l}\text { - Create an online platform decided at national level and developed for the whole country } \\
\text { - Develop training programs for SSS } \\
\text { - Develop guidelines at national level for decision-support on SSS technology selection and O\&M, fostering } \\
\text { "informed decisions" }\end{array}$ \\
\hline
\end{tabular}

2. Fostering coordination and harmonization between the governmental agencies concerned with smallscale sanitation through one single database, which (a) fills data gaps, and increase the transparency and accessibility of information; and (b) allows data analysis, statistics and mapping by all concerned governmental agencies.

3. Allowing monitoring of the contribution of SSS to the progress of wastewater management and water reuse, at national, state and city levels.

4. Allowing better integration of SSS in citywide urban sanitation planning, as well as in water reuse planning, through geo-localization and mapping of the SSTPs.

5. Simplifying administrative procedures through digitalization, in order to (a) avoid SSTP owners to physically visit several governmental agencies; (b) increase the transparency of the procedures and the ease to find and upload relevant documents; (c) streamline water sampling and direct upload of the results by accredited laboratories.

6. Allowing prioritization of monitoring visits based on automated verification procedures aimed at identifying potential risks or compliance failure; the water sampling data uploaded on the platform can be analyzed by simple algorithms performing plausibility checks (ratios between water parameters and variance of results over time), and the identification of contradictions or parameters exceeding thresholds.

7. Improving the efficiency of the available staff for SSTP monitoring, through automation and efficient data archiving.

8. Enabling learning through big data analysis of all existing SSTPs and the assessment of different types of systems and management schemes. 


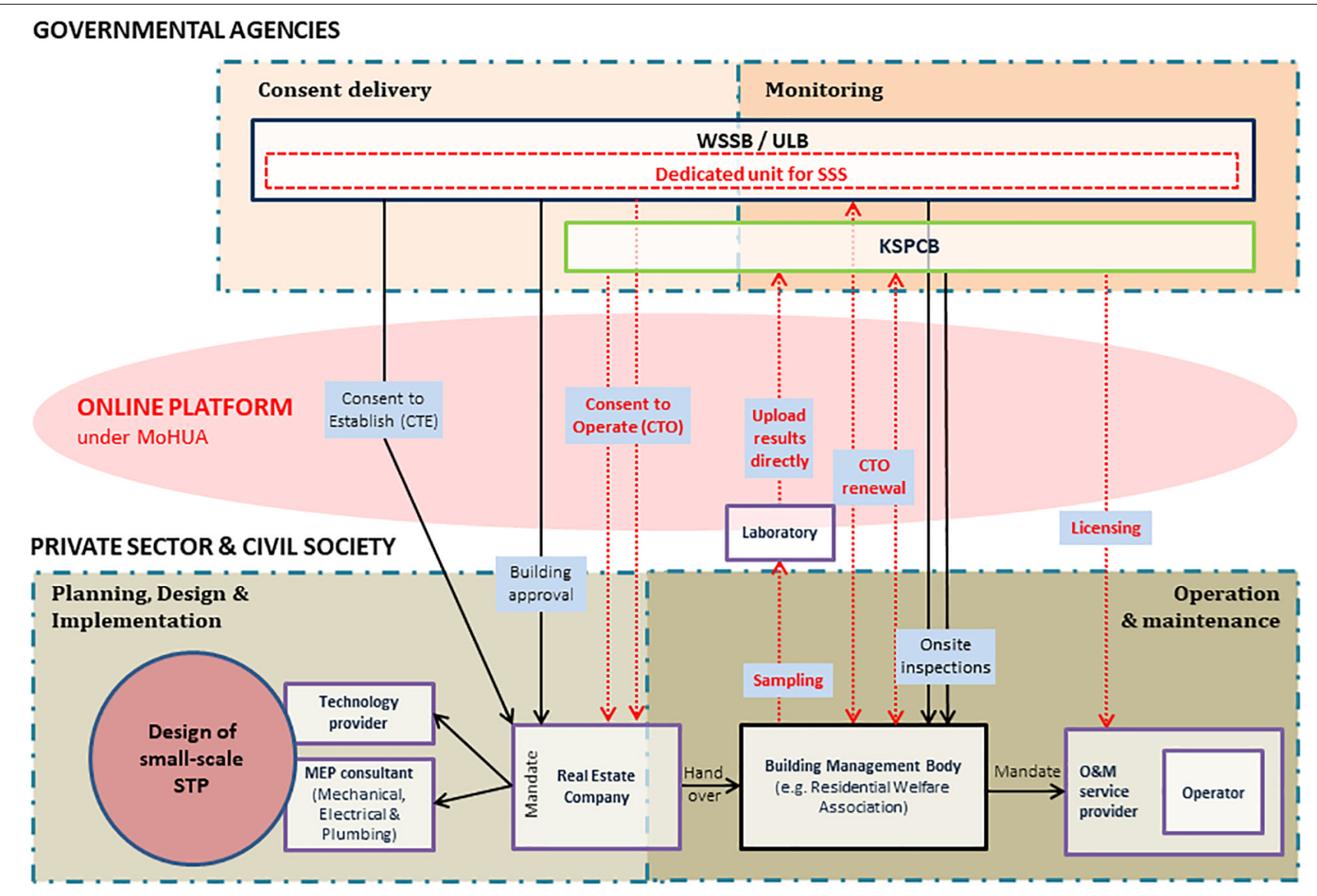

FIGURE 4 | New governance arrangements and streamlined procedures proposed by the authors (in red color).

9. Creating governmental SSS expert pools within the dedicated units, which would allow the provision of targeted training.

The authors assume that more effective hierarchical governance arrangements can lead to more coordination, more transparency and more information toward the private sector and civil society. In turn, this will enable the private sector and civil society to make better informed decision, foster learning, and enable feedback to relevant government agencies. Both structures would allow a better information flow between the government agencies, the private sector and the building owners. Reference documents can be made available on the online platform, and the SSS units can act as contact partners in case of queries regarding SSS.

Civil society participation is also crucial for the evaluation of innovative systems implemented at building level. Review of newspaper articles in Bengaluru highlighted that the lack of considerations of constraints on the ground when developing new policies, laws and regulations can result in a public outcry if there are not realistic to comply with in an affordable manner. The creation of network governance arrangements allowing two-way information flow between the relevant government agencies and civil society stakeholders is important in such a scaling up process.

The large number of SSTPs allows economies of scale, in terms of management, O\&M and capacity-building. Designbuild-operate contracting can raise accountability and the success rate of SSS. Companies providing O\&M services to several units need less staff and can access higher skills. Promoting delegated management to specialized private service providers can strengthen market governance, while setting clearer rules. This is in line with the postulate from Van De Meene et al. (2011), who advocate for hybrid governance arrangements at a practical and operational level, comprising network and hierarchical approaches with market governance instruments.

Network governance arrangements need to be fostered, both with SSTP operators and civil society organizations. The online platform can contribute to more network governance if data is available to all stakeholders and if it increases exchange between them. Information flows with civil society organizations such as building owners organizations need to be strengthened, and SSTP operators need to be linked to each other. The SSS units could include a hotline which can help SSTP operators to solve problems that they could not solve alone. Operator networks can be formed to help operators to support each other, prevent them from being isolated and allow 
them to participate in exchange or capacity-building events. Networks and collaborative arrangements showed promise in the countries which established decentralized water or wastewater management schemes in rural communities (WHO, 2016). Such schemes will result in an increase in capacities and efficiency, a higher level of professionalism in the sector and ultimately in increasing legitimacy for small-scale sanitation concepts (Harris-Lovett et al., 2015).

Skills in SSS are rare, and it is important to concentrate them. The creation of dedicated SSS units within city and state authorities, and the fostering of SSS O\&M companies, leads toward the concentration of expertise, which can then more easily be reinforced and multiplied. All the governmental agencies which are currently dealing with SSS are experiencing staff shortages. Especially in metropolitan cities, WSSBs are severely understaffed. Enhancing the institutional capacities and offering capacity-building on SSS should be a priority and go on par with implementation and enforcement of SSS policy. There is a need for guidance and capacity building for state level agencies and ULBs on how to integrate SSS systems next to large-scale systems and FSM. Governmental agencies can create training centers and curriculum about SSS. Malaysia successfully took this path of centralized management and capacity-building after a long period of trial and error with decentralized systems (Narayana, 2017).

\section{CONCLUSION: TOWARDS AN EFFICIENT GOVERNANCE FRAMEWORK FOR SMALL-SCALE WASTEWATER TREATMENT SYSTEMS}

This paper contributes to governance studies by substantiating the concept of hybrid governance approach (Pahl-Wostl, 2009, 2019) and by proposing concrete measures to make it work for distributed systems in a multi-level, polycentric governance framework like India: (a) Increasing the effectiveness and efficiency of hierarchical governance arrangements; (b) Fostering and optimizing the role of the private sector; (c) Creating network governance structures. It also provides insights into a regime shift toward citywide inclusive sanitation.

India presents a set of conditions for small-scale wastewater treatment systems to take a very significant role in increasing sanitation coverage and water security: fast urban growth, large middle- and high-income housing areas, water scarcity and urgent need for water reuse. The political drive is there, but hierarchical governance alone cannot work. This paper shows that for the successful scaling up of SSS requires: (a) a certain degree of market governance to enable the scaling up process; (b) a high degree of coordination between government agencies for a hierarchical governance approach to be effective and efficient in such a multi-level, polycentric governance framework. For the governance framework to be robust, it has to become an actively managed process with all key stakeholders on board.
Legitimation strategies are needed, as are robust monitoring and evaluation governance structures. Full recognition of SSS by MoHUA and line agencies would quickly allow the implementation of the measures proposed in this paper, and to overcome most of the identified weaknesses in the governance framework. The Government of India can make use of the strong skills available in the "Indian Silicon Valley" and "Digital India Mission" to implement online tools that will enable the necessary "centralized digital management" of small-scale wastewater treatment and reuse systems at scale.

In such a multi-level governance framework (national, state, and city), it is important to have selected centralized governance structures that ensure economies of scale in terms of information technologies development, knowledge management and trainings, and the harmonization of data management. It is crucial for the devolvement of competencies to city level, where capacities in the field of SSS need to be built. The whole system would also benefit from intermediary actors who would act as knowledge brokers and take over some coordination, training and knowledge transfer functions. More research is needed to define the optimal features of such intermediaries within the governance framework.

The use of digitalization and the creation of the governance structures that allow meaningful collaboration between stakeholders, facilitate learning and support robust O\&M and monitoring are at the core of the current thinking to fulfill the potential of alternative solutions for urban water management (Hoffmann et al., 2020). This paper provides a vision on how this could take shape in one of the contexts that is most advanced worldwide in the implementation of distributed systems in urban areas.

In 2017, the Government of Karnataka promoted a new urban wastewater reuse policy, to be implemented by a committee composed of representatives from the wastewater, industries and agriculture sectors. This new policy explicitly encourages decentralized treatment and reuse practices. The overall goal is to establish an enabling environment for the reuse of municipal wastewater to maximize efficient resource use, protect the environment, address water scarcity, and enhance economic output (KUDD, 2017). In particular, this policy initiates the development of a "Wastewater Resource Center" within the Urban Development Department, aimed at awareness and capacity-building, project assistance, performance monitoring and financing of wastewater reuse projects. Such committee has the potential to play the role of "intermediary" between the different stakeholders, a role that is essential for a robust governance framework. Such pioneering initiatives, involving representatives of the relevant government agencies, private sector and civil society can provide the required fertile soil on which promising governance innovations can grow, if they can remain autonomous and informal enough (Pahl-Wostl, 2009).

The effects of this policy on the ground are still to be seen, but it shows how dynamic the development of wastewater policies 
and regulations is in India. Some of the information collected within this paper may be quickly outdated. This only reinforces the belief that a strong multi-stakeholder platform and dedicated units are needed for the governance of small-scale sanitation, in order to be able to accommodate political changes and fulfill the potential of SSS in the sanitation landscape at national, state and city levels.

\section{DATA AVAILABILITY STATEMENT}

The datasets generated for this study are available on request to the corresponding author.

\section{ETHICS STATEMENT}

We believe that an ethical review process was not required for this study. We did not use citizen science. Information was collected through meetings with key sector stakeholders from different government agencies and private sector, who were all aware about our project. Oral informed consent was obtained for participation in this study, as a preliminary explanation of why we wanted to discuss these topics with them. Ethical approval and written informed consent was not required in line with local legislation. To be mentioned that this research was conducted in agreement with the Indian government.

\section{REFERENCES}

Abeysuriya, K., Mitchell, C., and White, S. (2007). Can corporate social responsibility resolve the sanitation question in developing Asian countries? Ecol. Econom. 62, 174-183. doi: 10.1016/j.ecolecon.2006. 06.003

Ahluwalia, I. (2011). Report on Indian Urban Infrastructure and Services. The High Powered Expert Committee (HPEC) for Estimating the Investment Requirements for Urban Infrastructure Services. Bangalore: India Water Portal.

Bhullar, L. (2013). Ensuring safe municipal wastewater disposal in urban india: is there a legal basis? J. Environ. Law 25, 235-260. doi: 10.1093/jel/eqt004

Binz, C., Harris-Lovett, S., Kiparsky, M., Sedlak, D., and Truffer, B. (2016). The thorny road to technology legitimation - Institutional work for potable water reuse in California. Technol. Forecast. Soc. Change 103, 249-263. doi: 10.1016/j. techfore.2015.10.005

Binz, C., and Truffer, B. (2017). Anchoring Global Networks in Urban Niches: How On-site Water Recycling Emerged in Three Chinese Cities. Urban Sustainability Transitions. Abingdon: Routledge, 23-36.

Binz, C., Truffer, B., and Coenen, L. (2015). Path creation as a process of resource alignment and anchoring: Industry formation for on-site water recycling in Beijing. Econom. Geogr. 92, 172-200. doi: 10.1080/00130095.2015.11 03177

Brown, R. R. (2005). Impediments to integrated urban stormwater management: the need for institutional reform. Environ. Manag. 36, 455-468. doi: 10.1007/ s00267-004-0217-4

Brown, R. R., and Farrelly, M. A. (2009). Delivering sustainable urban water management: a review of the hurdles we face. Water Sci. Technol. 59, 839-846. doi: 10.2166/wst.2009.028

Brunner, N., Lele, A., Starkl, M., and Grassini, L. (2010). Water sector reform policy in India: Experiences from case studies in Maharashtra. J. Policy Modell. 32, 544-561. doi: 10.1016/j.jpolmod.2010.04.001

\section{AUTHOR CONTRIBUTIONS}

PR was the main author and the lead of the governance analysis. RC did most of the data collection and policy review in India. His main contributions are in the context and results sections, and the development of the first draft of figures. LU was the project coordinator and participated in the data analysis and development of recommendations. His main contributions are in the recommendations section and discussion of the tables and figures.

\section{ACKNOWLEDGMENTS}

This work was completed as part of the $4 \mathrm{~S}$ Project (www. sandec.ch/4S), funded by the Bill \& Melinda Gates Foundation (main donor) and the German Federal Ministry for Economic Cooperation and Development, and implemented under the auspices of the Indian Ministry of Housing and Urban Affairs by the Swiss Federal Institute of Aquatic Science and Technology (Eawag), the Indian Institute of Technology Madras, BORDA, CDD Society, and other partners. The authors would like to thank Susmita Sinha, Sujaya Rathi, Christian Binz, and Abishek Sankara Narayan for their valuable comments and feedback, and the Water and Sanitation Innovations for Non-Grid Solutions program (WINGS) at Eawag (www.eawag.ch/wings). The authors' special thanks go to all the agencies and private stakeholders who participated in this study.

Chatterjee, P., Ghangrekar, M. M., and Rao, S. (2016). Low efficiency of sewage treatment plants due to unskilled operations in India. Environ. Chem. Lett. 14, 407-416. doi: 10.1007/s10311-016-0551-9

Davis, A., Javernick-Will, A., and Cook, S. M. (2019). The use of qualitative comparative analysis to identify pathways to successful and failed sanitation systems. Sci. Total. Envi. 663, 507-517. doi: 10.1016/j.scitotenv.2019.01.291

Eales, K., Siregar, R., Febriani, E., and Blackett, I. (2013). Review of Community Managed Decentralized Wastewater Treatment Systems in Indonesia. Report, 1st edition. Indonesia: WSP (World Bank).

Evans, B. (2013). "Sanitation in cities of the global south: Is decentralisation a solution?", in Source Separation and Decentralization for Wastewater Management, eds T. A. Larsen, K. M. Udert, and J. Lienert (London: IWA), 117-131.

Farrelly, M. A., and Brown, R. R. (2011). Rethinking urban water management: experimentation as a way forward. Glob. Environ. Change 21, 721-732. doi: 10.1016/j.gloenvcha.2011.01.007

Fischer, M., Ingold, K., and Ivanova, S. (2017). Information exchange under uncertainty: The case of unconventional gas development in the United Kingdom. Land Use Policy 67, 200-211. doi: 10.1016/j.landusepol.2017. 05.003

Gebauer, H., Haldimann, M., and Saul, C. J. (2017). Business model innovations for overcoming barriers in the base-of-the-pyramid market. Indus. Innov. 5, 543-568. doi: 10.1080/13662716.2017.1310033

Gebauer, H., and Saul, C. J. (2014). Business Model Innovation in the Water Sector in Developing Countries. Sci. Total Environ. 488-489, 512-520. doi: 10.1016/j. scitotenv.2014.02.046

Gikas, P., and Tchobanoglous, G. (2009). The role of satellite and decentralized strategies in water resources management. J. Environ. Manag. 90, 144-152. doi: 10.1016/j.jenvman.2007.08.016

GoK (2003). Proceedings of the Government of Karnataka: Restriction on use of drinking water for non-potable purposes in Bangalore City. Government Order No. FEE 188 ENV 2003, dated 14-08-2003. Bangalore: GoK. 
Harris-Lovett, S., Binz, C., Sedlak, D., Kiparsky, M., and Truffer, B. (2015). Beyond user acceptance: a legitimacy framework for potable water reuse in California. Environ. Sci. Technol. 49, 7552-7561. doi: 10.1021/acs.est.5b00504

Hoffmann, S., Feldmann, U., Bach, P. M., Binz, C., Farrelly, M., Frantzeskaki, N., et al. (2020). A research agenda for the future of urban water management: Exploring the potential of non-grid, small-grid, and hybrid solutions. Environ. Sci. Technol. 54, 5312-5322. doi: 10.1021/acs.est.9b0 5222

Klinger, M., Ulrich, L., Wolf, A. T., Reynaud, N., Philip, L., and Lüthi, C. (2020). Technology, Implementation and Operation of Small-scale Sanitation in India Performance Analysis and Policy Recommendations. 4S Project Report Vol. I. Available online at: www.sandec.ch/4S (accessed May 25, 2020).

Knoke, D. (1996). Comparing Policy Networks: Labor Politics in the US, Germany, and Japan. Cambridge: Cambridge University Press.

KSPCB (2015). Directions Under Section 33(A) of the Water (Prevention \& Control of Pollution) Act, 1974 regarding treatment and utilization of sewage. Order No. PCB/074/STP/2012/4975, 05 December 2015. Bangalore: KSPCB.

KUDD (2017). Policy for Urban Waste Water Reuse - Enabling Environment for Urban Wastewater Reuse. Bermuda Dunes, CA: KUDD.

Kuttuva, P., Lele, S., and Mendez, G. V. (2018). Decentralized Wastewater Systems in Bengaluru, India: Success or Failure? Water Econ. Policy 4, 1-22. doi: 10.1142/ S2382624X16500430

Larsen, T., Hoffmann, S., Lüthi, C., Truffer, B., and Maurer, M. (2016). Emerging solutions to the water challenges of an urbanizing world. Science 352, 928-933. doi: $10.1126 /$ science.aad 8641

Larsen, T. A., Udert, K. M., and Lienert, J. (Eds). (2013). Source Separation and Decentralization for Wastewater Management. London: IWA Publishing.

Libralato, G., Volpi, G. A., and Avezzù, F. (2012). To centralise or to decentralise: an overview of the most recent trends in wastewater treatment management. J. Environ. Manag. 94, 61-68. doi: 10.1016/j.jenvman.2011.07.010

Lüthi, C., and Panesar, A. (2013). "Source separation in middle- and lowincome countries," in Source Separation and Decentralization for Wastewater Management, eds T. A. Larsen, K. M. Udert, and J. Lienert (London: IWA), $455-462$.

Massoud, M. A., Tarhini, A., and Nasr, J. A. (2009). Decentralized approaches to wastewater treatment and management: applicability in developing countries. J. Environ. Manag. 90, 652-659. doi: 10.1016/j.jenvman.2008.07.001

Maurer, M. (2009). Specific net present value: An improved method for assessing modularisation costs in water services with growing demand. Water Res. 43, 2121-2130. doi: 10.1016/j.watres.2009.02.008

McKinsey (2014). An integrated water management strategy for Bengaluru. Report. Confederation of Indian Industry. Bangalore: McKinsey.

Mitchell, C., Ross, K., and Abeysuriya, K. (2015). An analysis of performance data for local scale wastewater services in Indonesia. Prepared by the Institute for Sustainable Futures, University of Technology Sydney, as part of the Australian Development Research Award Scheme (ADRAS) Project: Effective governance for the successful long-term operation of local scale wastewater systems. Sydney: Institute for Sustainable Futures.

Mitchell, V. G. (2006). Applying integrated urban water management concepts: a review of Australian experience. Environ. Manag. 37, 589-605. doi: 10.1007/ s00267-004-0252-1

MoE (2018). Night Soil Treatment and Decentralized Wastewater Treatment Systems in Japan. Ministry of Environment. New Delhi: MoE.

MoEF (2004). Ministry of Environment and Forests - Notification S.O. 801(E), $7^{\text {th }}$ July 2004 . Gazette of India. New Delhi: MoEF.

MoEF (2006). Ministry of Environment and Forests - Notification S.O. 1533, $14^{\text {th }}$ September 2006. Gazette of India. New Delhi: MoEF.

MoUD (2008). National Urban Sanitation Policy. New Delhi: Government of India.

MoWR (2012). National Water Policy. New Delhi: Government of India.

Narayana, D. (2017). "Sanitation and sewerage management: the Malaysian experience," in FSM Innovation: Case Studies on the Business, Policy and Technology of Faecal Sludge Management, eds I. Blackett and P. Hawkins (Seattle, WA: BMGF).

Never, B. (2016). Wastewater Systems and Energy Saving in Urban India - Governing the Water-Energy-Food Nexus Series. Available online at: https://ssrn.com/ abstract=2811524 (accessed July 19, 2016).
Newman, P. (2001). Sustainable urban water systems in rich and poor cities-steps towards a new approach. Water Sci. Technol. 43, 93-99. doi: 10.2166/wst.2001. 0188

Pahl-Wostl, C. (2009). A conceptual framework for analysing adaptive capacity and multi-level learning processes in resource governance regimes. Glob. Environ. Change 19, 354-365. doi: 10.1016/j.gloenvcha.2009.06.001

Pahl-Wostl, C. (2019). The role of governance modes and meta-governance in the transformation towards sustainable water governance. Environ. Sci. Policy 91, 6-16. doi: 10.1016/j.envsci.2018.10.008

Parkinson, J., and Tayler, K. (2003). Decentralized wastewater management in peri-urban areas in low-income countries. Environ. Urbani. 15, 75-90. doi: $10.1177 / 095624780301500119$

Planning Commission (2011). Report of the Working Group on Urban and Industrial Water Supply and Sanitation for the Twelfth Five-Year-Plan (20122017). New Delhi: Planning Commission.

Reymond, P., Abdel Wahaab, R., Moussa, M. S., and Lüthi, C. (2018). Scaling up small scale wastewater treatment systems in low- and middle-income countries: An analysis of challenges and ways forward through the case of Egypt. Utilities Policy 52, 13-21. doi: 10.1016/j.jup.2018.03.008

Reymond, P., Renggli, S., and Lüthi, C. (2016). "Towards Sustainable Sanitation in an Urbanising World," in Sustainable Urbanization, ed. M. Ergen (London: InTech Publishing), doi: 10.5772/63726

Ross, K., Abeysuriya, K., Mikhailovich, N., and Mitchell, C. (2014). Governance for decentralised sanitation: Global Practice Scan. A working document. Prepared by the Institute for Sustainable Futures, UTS as part of the Australian Development Research Award Scheme (ADRAS). Sydney: Institute for Sustainable Futures.

Sakthivel, P., Elango, L., Amirthalingam, S., Pratap, C. E., Brunner, N., Starkl, M., et al. (2015). Managed aquifer recharge: the widening gap between law and policy in India. Water Sci. Technol. Water Supply 15, 1159-1165. doi: 10.2166/ws.2015.074

Singh, A., Kazmi, A., Starkl, M., Sayanekar, S., and Herlekar, M. (2018). Sewage management challenges in mega cities in India: a case study from Mumbai. Desal. Water Treat. 116, 329-341. doi: 10.5004/dwt.2018. 22448

Singh, N. K., Kazmi, A. A., and Starkl, M. (2015). A review on full-scale decentralized wastewater treatment systems: Techno-economical approach. Water Sci. Technol. 71, 468-478. doi: 10.2166/wst.2014.413

Srinavas, A. (2018). Waste Water Everywhere? Recycle It. Chennai: Hindu Businessline.

Starkl, M., Aymerich, E., Brunner, N., Chubilleau, C., Das, S., Ghangrekar, M., et al. (2018). Interpreting best available technologies more flexibly: a policy perspective for municipal wastewater management in India and other developing countries. Environ. Impact Assess. Rev. 71, 132-141. doi: 10.1016/j. eiar.2018.03.002

Starkl, M., Brunner, N., and Stenström, T.-A. (2013). Why do water and sanitation systems for the poor still fail? Policy analysis in economically advanced developing countries. Environ. Sci. Technol. 47, 6102-6110. doi: 10.1021/ es3048416

Suneethi, S., Keerthiga, G., Soundhar, R., Kanmani, M., Boobalan, T., Krithika, D., et al. (2015). Qualitative evaluation of small-scale municipal wastewater treatment plants in South India. Water Pract. Technol. 10, 711-719. doi: 10. 2166/wpt.2015.087

Truffer, B., Binz, C., Gebauer, H., and Störmer, E. (2013). "Market success of on-site treatment: a systemic innovation problem," in Source Separation and Decentralization for Wastewater Management, 1st Edn, eds T. A. Larsen, K. M. Udert, and J. Liener (London: IWA Publishing), 209-223.

Ulrich, L. (2018). A Roadmap for Small-scale Sanitation in India: Fulfilling its Potential for Healthy and Water-Secure Cities. 4S Synthesis Report. Available online at: www.sandec.ch/4S (accessed 5 April 2018).

UNDP-SIWI (2016a). WGF Issue sheet: Sanitation Governance. Water Governance Facility. Stockholm: SIWI.

UNDP-SIWI (2016b). WGF Issue sheet: Water Governance. Water Governance Facility. Stockholm: SIWI.

Van De Meene, S. J., Brown, R. R., and Farrelly, M. A. (2011). Towards understanding governance for sustainable urban water management. Glob. Environ. Change 21, 1117-1127. doi: 10.1016/j.gloenvcha.2011.04.003 
Vlachos, E., and Braga, B. (2001). "The challenge of urban water management," in Frontiers in Urban Water Management: Deadlock or Hope, eds C. Maksimovic and J. A. Tejada-Guibert (London: IWA Publishing), 1-36.

Wankhade, K. (2015). Urban sanitation in India: key shifts in the national policy frame. Environ. Urban. 27, 555-572. doi: 10.1177/09562478145 67058

Wescoat, J. L., Fletcher, S., and Novellino, M. (2016). National rural drinking water monitoring: progress and challenges with India's IMIS database. Water Policy 18, 1015-1032. doi: 10.2166/wp.2016.158

WHO (2016). "Taking policy action to improve small-scale water supply and sanitation systems," in Tools And Good Practices From The Pan-European Region, eds B. Rickert, E. Barrenberg, and O. Schmoll (Geneva: WHO).

Wilderer, P. A., and Schreff, D. (2000). Decentralised and centralised wastewater management: a challenge for developers. Water Sci. Technol. 41, 1-8. doi: 10. 2166/wst.2000.0001
Willetts, J., Fane, S., and Mitchell, C. (2007). Making decentralised systems viable: a guide to managing decentralised assets and risks. Water Sci. Technol. 56, 165-173. doi: 10.2166/wst.2007.569

Conflict of Interest: PR and LU were employed by the Eawag at the time of study.

The remaining author declares that the research was conducted in the absence of any commercial or financial relationships that could be construed as a potential conflict of interest.

Copyright $\odot 2020$ Reymond, Chandragiri and Ulrich. This is an open-access article distributed under the terms of the Creative Commons Attribution License (CC BY). The use, distribution or reproduction in other forums is permitted, provided the original author(s) and the copyright owner(s) are credited and that the original publication in this journal is cited, in accordance with accepted academic practice. No use, distribution or reproduction is permitted which does not comply with these terms. 